\title{
Incidence, life expectancy and prognostic factors in cancer patients under prolonged mechanical ventilation: a nationwide analysis of 5,138 cases during 1998-2007
}

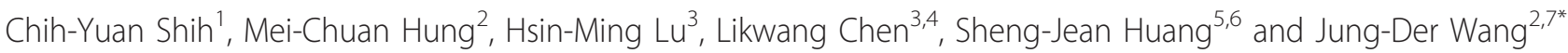

\begin{abstract}
Introduction: This study is aimed at determining the incidence, survival rate, life expectancy, quality-adjusted life expectancy (QALE) and prognostic factors in patients with cancer in different organ systems undergoing prolonged mechanical ventilation (PMV).

Methods: We used data from the National Health Insurance Research Database of Taiwan from 1998 to 2007 and linked it with the National Mortality Registry to ascertain mortality. Subjects who received PMV, defined as having undergone mechanical ventilation continuously for longer than 21 days, were enrolled. The incidence of cancer patients requiring PMV was calculated, with the exception of patients with multiple cancers. The life expectancies and QALE of patients with different types of cancer were estimated. Quality-of-life data were taken from a sample of 142 patients who received PMV. A multivariable proportional hazards model was constructed to assess the effect of different prognostic factors, including age, gender, type of cancer, metastasis, comorbidities and hospital levels.

Results: Among 9,011 cancer patients receiving mechanical ventilation for more than 7 days, 5,138 undergoing PMV had a median survival of 1.37 months (interquartile range [IQR], 0.50 to 4.57) and a 1-yr survival rate of $14.3 \%$ (95\% confidence interval [CI], 13.3\% to 15.3\%). The incidence of PMV was 10.4 per 100 ICU admissions. Head and neck cancer patients seemed to survive the longest. The overall life expectancy was 1.21 years, with estimated QALE ranging from 0.17 to 0.37 quality-adjusted life years for patients with poor and partial cognition, respectively. Cancer of liver (hazard ratio [HR], 1.55; 95\% Cl, 1.34 to 1.78), lung (HR, 1.45; 95\% Cl, 1.30 to 1.41) and metastasis (HR, $1.53 ; 95 \% \mathrm{Cl}, 1.42$ to 1.65$)$ were found to predict shorter survival independently.
\end{abstract}

Conclusions: Cancer patients requiring PMV had poor long-term outcomes. Palliative care should be considered early in these patients, especially when metastasis has occurred.

\section{Introduction}

The number of cancer patients has been steadily increasing, and cancer has become the leading cause of death in many countries $[1,2]$. Patients with malignancies are at risk of developing acute respiratory failure due to the underlying cancer as well as to its treatment, and many of these patients will need mechanical ventilation support while in the ICU. In hospitalized patients with solid

\footnotetext{
* Correspondence: jdwang121@gmail.com

${ }^{2}$ Department of Public Health, National Cheng Kung University College of

Medicine, No.1, University Road, Tainan 701, Taiwan Full list of author information is available at the end of the article
}

tumors, approximately $1 \%$ have been diagnosed with acute respiratory failure [3]. The incidence varies from $9 \%$ to almost half of the population in patients with hematologic malignancies $[3,4]$. Studies of patients with cancer admitted to ICUs have demonstrated that mechanical ventilation has been provided for $42 \%$ to $83 \%$ of these patients [3,5-9].

The number of patients requiring prolonged mechanical ventilation (PMV), defined as having undergone mechanical ventilation continuously for longer than 21 days, is rapidly increasing because of the advances in intensive care [10]. During 2009, approximately 30,000 patients
Ciomed Central 
required PMV as recorded by the National Health Insurance (NHI) of Taiwan, which accounted for $4.76 \%$ of total $\mathrm{NHI}$ healthcare expenditures. This financial burden has now become one of the major threats to the sustainability of the NHI [11,12]. In our previous study, cancer patients requiring PMV account for up to $10.6 \%$ of all PMV patients [13]. Although the NHI reimburses all the direct healthcare expenditures of these patients, there is still outof-pocket money spent for indirect care by the patients' families that results in a financial burden [14]. Moreover, withdrawal of mechanical ventilation was not legally allowed in Taiwan before 2011. Thus, it would help patients and their families to know which patients are least likely to survive on a long-term basis so that further invasive interventions could be reconsidered.

Therefore, accurate prognoses are essential to propose and establish a sustainable national policy and to facilitate communication among different stakeholders. There is limited information on lifetime outcomes in cancer patients who have required PMV. The aims of this study were to determine the incidence and life expectancy of cancer patients requiring PMV and to identify factors associated with lifetime survival, as well as the qualityadjusted life expectancy (QALE) of cancer patients undergoing PMV.

\section{Materials and methods}

\section{Study population and data sets}

The current study was approved by the Institutional Review Board of National Taiwan University Hospital (IRB 200912072R). We retrieved the data from the National Health Insurance Research Database (NHIRD), a reimbursement data file that we obtained from the NHI of Taiwan. It was transformed into a research database by the National Health Research Institutes (Chunan, Taiwan). The identification numbers of all individuals in the reimbursement data file were encrypted to protect the patients' privacy. These files contained detailed demographic data (including birthdate and gender) and information regarding the healthcare services provided for each patient, including all payments for outpatient visits, hospitalizations, prescriptions and intervention procedures. In addition, up to five diagnoses were provided for the hospitalization. In total, 8,906,406 individuals had undergone invasive or noninvasive respiratory care at least once during the period from 1997 to 2007. This number corresponds to approximately $29.4 \%$ of the entire insured population. Because the government has established guidelines stating that no more than $10 \%$ of all data can be drawn for research, we applied for a random sample of these patients with a 3.4:1 sampling ratio. Namely, 1 record of a patient who had undergone respiratory care was randomly drawn from every 3.4 records so that the total data would be close to the $10 \%$ limit. Subjects who were over the age of 17 years and had undergone extended mechanical ventilation for longer than 7 days were enrolled, wherein PMV was defined as patients requiring more than 21 days of mechanical ventilation $[15,16]$. To ensure that all of the patients were incident cases, we excluded all prevalent cases found in 1997 and began the collection in 1998. To select cancer patients, we linked our data set with the registry of cancer under NHIRD catastrophic illness and excluded cases with multiple cancer diagnoses, as summarized in Figure 1. The incidences were the risks of PMV among different types of cancer patients admitted to the ICU during a period from 1998 to 2007.

\section{Statistical analysis}

\section{Determinants or prognostic factors of survival}

Age, gender, hospital level and comorbidities were included as the major determinants with which to explore the survival of these patients. Differences in survival were examined across gender and four categories of age (younger than 65, 65 to 74,75 to 84 , and 85 years and older). The hospital level was retrieved from the NHI claim codes and was classified into district hospital (usually fewer than 250 beds), regional hospital (usually 250 to 1,000 beds) or medical center (usually more than 1,000 beds). The data for each inpatient hospitalization included up to five diagnoses, which were coded according to the International Classification of Diseases, Ninth Revision, Clinical Modification. The diagnoses were reclassified into 260 categories according to the Clinical Classifications Software (CCS) for ICD-9-CM [17]. The classification of cancer types and metastatic status in our study were simplified from the multilevel CCS codes to collect sufficient numbers of subcohorts. Comorbidities were identified from the single-level CCS and reclassified into 40 broad categories excluding cancer. Comorbidities occurring in less than $5 \%$ of the PMV study population were excluded. Univariate Cox regression analysis was used first to examine the correlation between each prognostic variable and the length of survival. Spearman's rank correlation was calculated to explore any collinearity between the studied variables. Multivariable Cox regression analyses were performed to determine the prognostic impact of cancer types after adjusting for potential confounding variables. Variables considered in the models included gender, four categories of age, period of receiving PMV treatment (1998 to 2000, 2001 to 2004 and 2005 to 2007), extent of cancer (local vs metastasis), cancer types (organ system or location), acute comorbidities, concurrent organ disorder (chronic comorbidities) and hospital level (district hospital, regional hospital or medical center). Stepwise selection processes were applied to select the comorbidities of prognostic relevance. Acute and chronic comorbidities were 
Patients with one or more order codes of respiratory care between

$1997-2007$ in the National Health Insurance database $(N=8,906,406)$

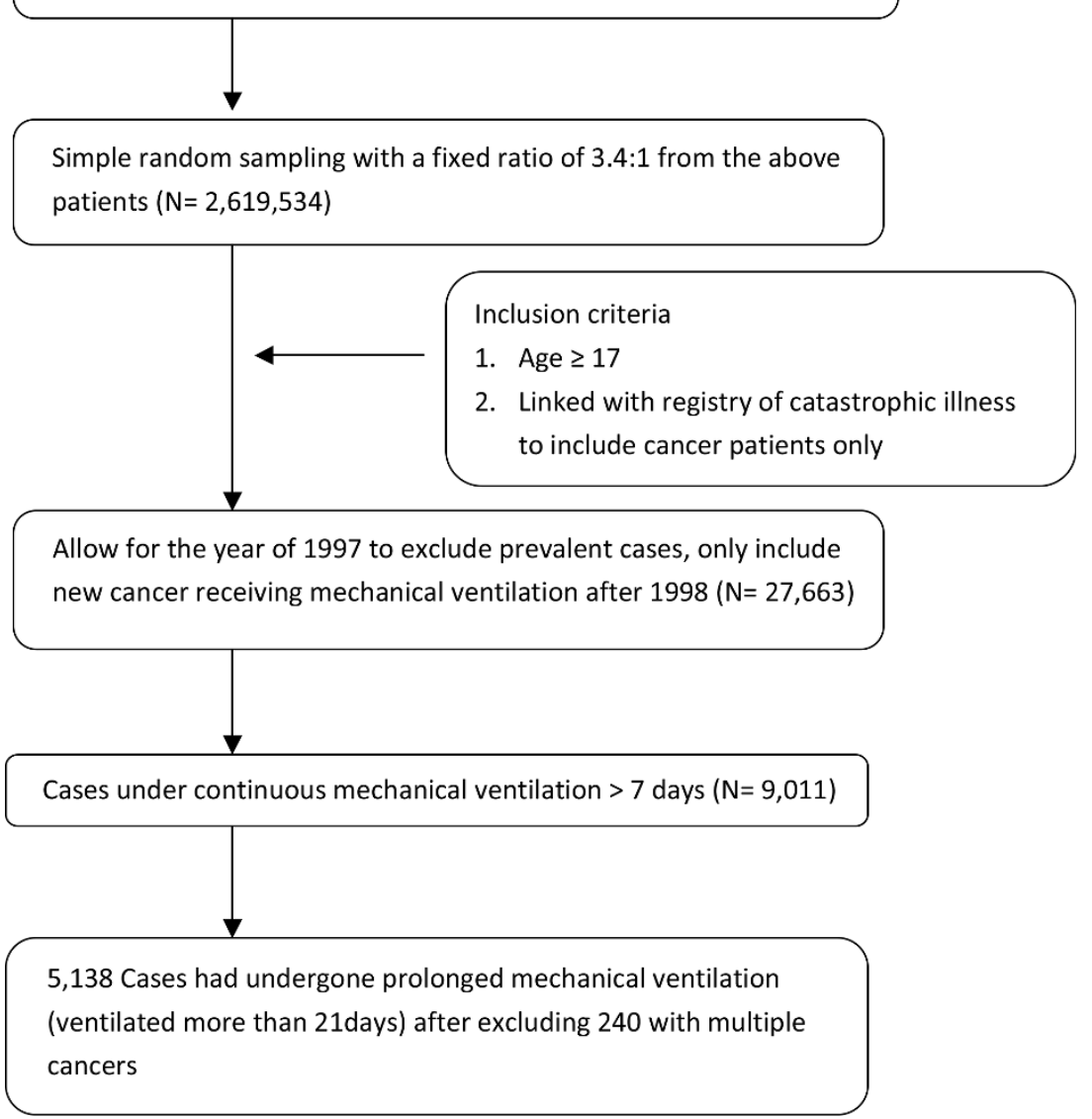

Figure 1 Flow diagram of selection process used for the study cohort.

considered both separately and concurrently in the Cox regression models. All statistical analyses were performed by using SAS version 9.1 software (SAS Institute, Cary, NC, USA).

\section{Survival analysis and estimation of life expectancy}

Each new patient who fulfilled the definition of mechanical ventilation was followed from the seventh day of mechanical ventilation until he or she died or was censored on 31 December, 2007. The median survival and long-term survival rates were estimated using the Kaplan-Meier method. Patients who survived more than 21 days were followed under an integrated system of reduced intensive respiratory care [18]. Their lifetime survival was estimated up to 300 months using a linear extrapolation of a logit-transformed curve for the survival ratio between the PMV and an age- and gender-matched reference population generated by the Monte Carlo method from the life table of the general population of Taiwan (Figure 2). The detailed method and mathematical proof assuming a constant excess hazard were described in our previous reports
[19-21]. To facilitate computation, we used iSQoL, a software program that was built on the $\mathrm{R}$ programming language for lifetime expectancy estimation and 300-month extrapolation that can be downloaded for free from the website [22].

\section{Estimation of quality-adjusted life expectancy}

The lifetime survival probabilities along the duration to dates (or time after PMV onset) were multiplied (or adjusted) with the quality-of-life (QoL) values to obtain a quality-adjusted survival curve. The sum of the total area under this curve was the QALE with quality-adjusted life years (QALYs) as the common unit [23]. Our QoL data were taken from a sample of 142 patients under PMV and measured using the EQ-5D Health Questionnaire and were classified into either partial or poor cognition [24,25]. Partial cognition was defined as an Mini Mental State Examination score higher than 15. Poor cognition was categorized as scores equal to or less than 15. The detailed estimation method was summarized and reported in a previous article evaluating the cost-effectiveness of PMV treatment [14]. 
a.

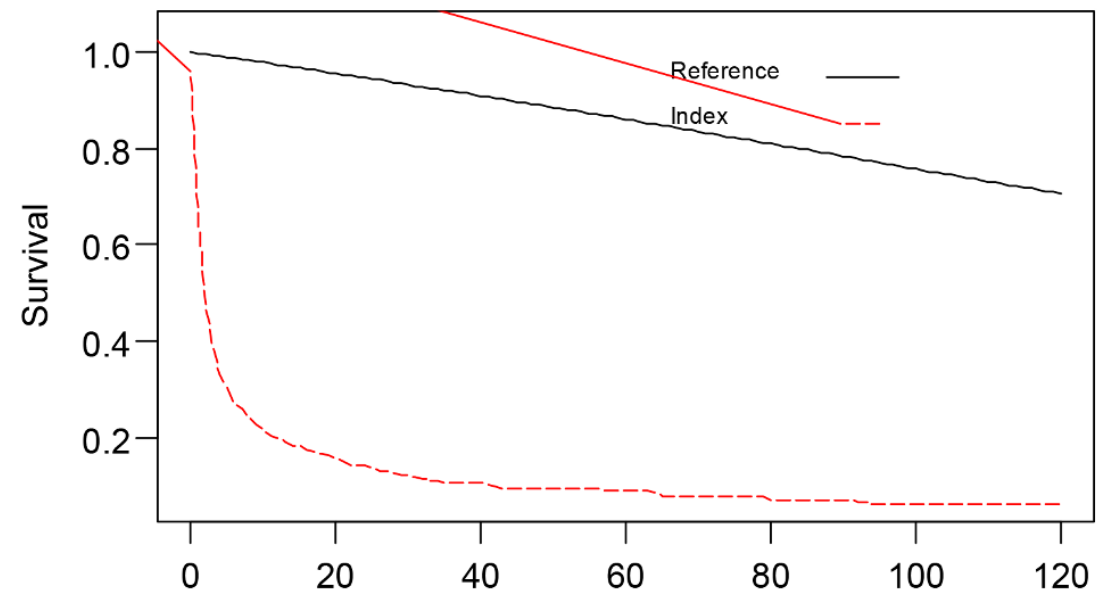

Time in months

b.

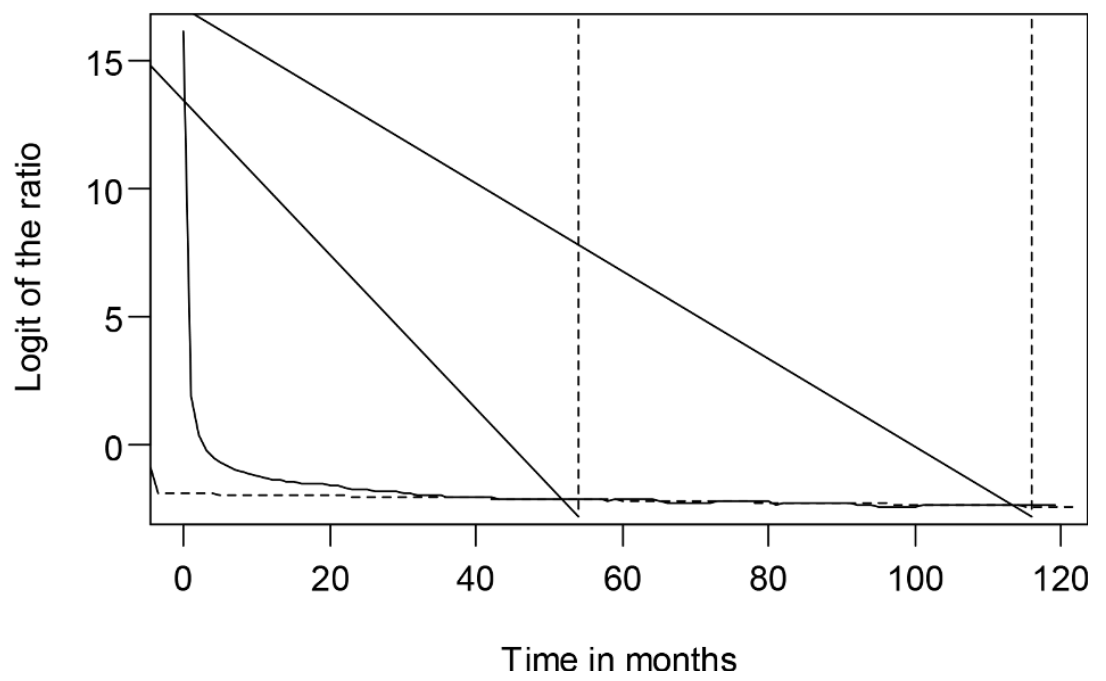

Figure 2 Survival analysis and estimation of life expectancy. (A) Estimated survival curve for patients with head and neck cancer undergoing prolonged mechanical ventilation (indicated by dashed line) and age- and gender-matched referents generated by Monte Carlo method based on life tables of vital statistics of Taiwan. (B) Plot of logit-transformed curve of the survival ratio between index and referents populations showing the fulfillment of constant excess hazard.

\section{Results}

\section{Patient characteristics}

A total of 9,011 cancer patients under extended mechanical ventilation were included during the study period. The median survival was generally less than 2 months, and the 1 -yr survival rate was mostly less than $20 \%$. Among those patients studied, 5,138 had undergone mechanical ventilation for more than 21 days. Their mean age was 69.1 years $(\mathrm{SD} \pm 13.8)$, and $33 \%$ were females. The median survival was 1.37 months (interquartile range [IQR], 0.50 to 4.57 )
(Table 1), which is slightly longer than the 1.13 months (IQR, 0.47 to 4.30 ) of the 240 excluded cases with multiple cancers. About one-third of the cases were patients with cancers occurring in the head and neck or in the respiratory tract. About one-fourth were metastasized cancers, indicating that advanced cancer patients treated with PMV were not uncommon. The most frequently encountered acute comorbidities were septicemia (22.4\%), followed by gastrointestinal hemorrhage (10.9\%) and shock $(10.6 \%)$. 
Table 1 Characteristics and survival of cancer patients categorized by duration of mechanical ventilation (1998 to 2007). a $^{2}$

\begin{tabular}{|c|c|c|c|c|c|c|c|}
\hline \multirow[b]{3}{*}{ Variables } & \multicolumn{7}{|c|}{ Duration of mechanical ventilation } \\
\hline & \multicolumn{3}{|c|}{$>7$ days (extended MV) } & \multicolumn{4}{|c|}{$>21$ days (prolonged $\mathrm{MV}$ ) } \\
\hline & $N$ & $\begin{array}{l}\text { Median survival, } \\
\text { months (IQR) }\end{array}$ & $\begin{array}{l}\text { 1-yr survival rate, } \\
\%(95 \% \mathrm{Cl})\end{array}$ & $N$ & $\begin{array}{l}\text { Median survival, } \\
\text { months (IQR) }\end{array}$ & $\begin{array}{l}\text { 1-yr survival rate, } \\
\%(95 \% \mathrm{Cl})\end{array}$ & $\begin{array}{l}\text { Life } \\
\text { expectancy, } \\
\text { yr (SE) }\end{array}$ \\
\hline Total & 9,011 & 1.54 (0.67 to 5.90$)$ & $17.6(16.8$ to 18.4$)$ & 5138 & $1.37(0.50$ to 4.57$)$ & $14.3(13.3$ to 15.3$)$ & $1.21(0.10)$ \\
\hline \multicolumn{8}{|l|}{ Gender and age (yr) } \\
\hline \multicolumn{8}{|l|}{ Male } \\
\hline 17 to 64 & 2,282 & 1.64 (0.66 to 8.29$)$ & 20.4 (18.8 to 22.2$)$ & 1,010 & $1.17(0.43$ to 3.73$)$ & $13.9(11.8$ to 16.2$)$ & $1.52(0.22)$ \\
\hline 65 to 74 & 1,686 & 1.50 (0.67 to 5.10$)$ & 16.7 (14.9 to 18.5$)$ & 986 & $1.37(0.50$ to 4.23$)$ & $12.8(10.8$ to 15.1$)$ & $1.02(0.13)$ \\
\hline 75 to 84 & 1,729 & 1.50 (0.70 to 4.94$)$ & $15.1(13.4$ to 16.9$)$ & 1,116 & $1.40(0.53$ to 4.63$)$ & $13.3(11.3$ to 15.4$)$ & $0.86(0.09)$ \\
\hline 85 or older & 425 & $1.64(0.77$ to 4.50$)$ & $14.9(11.6$ to 18.6$)$ & 318 & $1.80(0.63$ to 4.73$)$ & 16.4 (12.4 to 20.9$)$ & $0.95(0.19)$ \\
\hline \multicolumn{8}{|l|}{ Female } \\
\hline 17 to 64 & 1,129 & 1.40 (0.60 to 6.84$)$ & $19.8(17.5$ to 22.3$)$ & 573 & $1.30(0.43$ to 5.43$)$ & $17.2(14.2$ to 20.5$)$ & $1.49(0.31)$ \\
\hline 65 to 74 & 788 & $1.54(0.64$ to 5.27$)$ & $17.2(14.6$ to 20.0$)$ & 459 & 1.40 (0.63 to 4.53$)$ & $13.9(10.9$ to 17.3$)$ & $1.03(0.24)$ \\
\hline 75 to 84 & 727 & 1.50 (0.67 to 5.50$)$ & 14.3 (11.8 to 17.1$)$ & 499 & 1.47 (0.57 to 5.83$)$ & 14.8 (11.7 to 18.2$)$ & $1.07(0.30)$ \\
\hline 85 or older & 234 & 1.84 (0.86 to 6.67$)$ & 17.6 (12.9 to 23.0) & 177 & $1.70(0.73$ to 6.20$)$ & 16.4 (11.1 to 22.6$)$ & $0.82(0.24)$ \\
\hline \multicolumn{8}{|l|}{ Extent of cancer } \\
\hline Local & 5,954 & 1.87 (0.79 to 8.32 ) & 20.6 (19.5 to 21.7$)$ & 3,900 & 1.60 (0.57 to 5.97$)$ & 16.9 (15.7 to 18.2$)$ & $1.36(0.11)$ \\
\hline Metastasis & 3,057 & 1.07 (0.50 to 3.12 ) & $11.7(10.6$ to 12.9$)$ & 1,238 & 0.93 (0.37 to 2.10$)$ & $5.9(4.6$ to 7.3$)$ & $0.64(0.15)$ \\
\hline \multicolumn{8}{|l|}{ Cancer type } \\
\hline Head and neck & 1,432 & 2.60 (0.89 to 13.32$)$ & 26.0 (23.7 to 28.3$)$ & 705 & 1.77 (0.70 to 7.57$)$ & $20.0(17.0$ to 23.1$)$ & $1.57(0.45)$ \\
\hline $\begin{array}{l}\text { Bone and connective } \\
\text { tissue }\end{array}$ & 52 & 1.37 (0.77 to 2.74$)$ & $10.0(3.7$ to 20.1$)$ & 38 & 0.87 (0.37 to 1.77 ) & 2.8 (2.1 to 12.2$)$ & $-\mathrm{b}$ \\
\hline Liver & 775 & 0.87 (0.40 to 2.50$)$ & 10.5 (8.4 to 12.8$)$ & 297 & 1.00 (0.40 to 2.43$)$ & 6.8 (4.2 to 10.2$)$ & $0.45(0.19)$ \\
\hline Lung & 1,752 & 1.10 (0.56 to 2.93 ) & $10.5(9.1$ to 12.1$)$ & 965 & 1.00 (0.37 to 2.57$)$ & 6.6 (5.1 to 8.3 ) & $0.77(0.13)$ \\
\hline Esophagus & 495 & 2.07 (0.86 to 9.17) & 22.5 (18.8 to 26.3 ) & 232 & 1.03 (0.47 to 2.83 ) & 10.2 (6.6 to 14.6$)$ & $0.98(0.33)$ \\
\hline $\begin{array}{l}\text { Lymphatic and } \\
\text { hematopoietic tissue }\end{array}$ & 578 & 1.20 (0.57 to 4.47$)$ & 14.2 (11.5 to 17.2$)$ & 289 & 1.27 (0.43 to 4.33$)$ & 14.3 (10.4 to 18.7$)$ & $1.12(0.36)$ \\
\hline Urinary organs & 420 & 1.74 (0.90 to 4.94$)$ & $16.0(12.6$ to 19.8$)$ & 306 & 1.30 (0.60 to 3.87 ) & $12.8(9.2$ to 16.9$)$ & $0.88(0.22)$ \\
\hline Female genital & 345 & 1.37 (0.67 to 5.37$)$ & $17.2(13.4$ to 21.5$)$ & 214 & $1.23(0.50$ to 5.23$)$ & 14.1 (9.8 to 19.3 ) & $0.98(0.63)$ \\
\hline $\begin{array}{l}\text { Pancreas and other } \mathrm{Gl} \\
\text { organs }\end{array}$ & 176 & 1.27 (0.61 to 3.57$)$ & $13.2(8.6$ to 18.7$)$ & 99 & 1.33 (0.43 to 4.90$)$ & 15.1 (8.9 to 22.9) & $-\mathrm{b}$ \\
\hline Stomach & 503 & 1.57 (0.74 to 5.44$)$ & 17.7 (14.4 to 21.3$)$ & 305 & $1.60(0.60$ to 5.60$)$ & 17.0 (12.9 to 21.6$)$ & $0.98(0.38)$ \\
\hline Thyroid & 77 & 1.81 (0.87 to 10.34$)$ & 24.9 (15.7 to 35.2$)$ & 56 & $1.27(0.50$ to 5.17$)$ & 18.6 (9.5 to 30.0 ) & $-{ }^{b}$ \\
\hline Breast & 375 & 1.40 (0.57 to 4.97$)$ & 17.1 (13.3 to 21.3) & 223 & $1.40(0.60$ to 6.47$)$ & 18.9 (13.8 to 24.6$)$ & $1.17(0.48)$ \\
\hline Skin & 100 & 2.30 (0.97 to 9.10$)$ & 21.3 (13.7 to 30.0$)$ & 83 & 1.83 (0.60 to 6.33 ) & 18.1 (10.6 to 27.3$)$ & $-{ }^{b}$ \\
\hline $\begin{array}{l}\text { Brain and nervous } \\
\text { system }\end{array}$ & 280 & 2.40 (1.17 to 7.60$)$ & $18.0(13.5$ to 23.0$)$ & 228 & 1.97 (0.83 to 7.13$)$ & 15.8 (11.2 to 21.2$)$ & $1.18(0.50)$ \\
\hline Colorectal & 1,019 & 1.91 (0.80 to 9.60$)$ & 22.8 (20.2 to 25.5$)$ & 650 & 1.77 (0.60 to 7.07$)$ & 18.8 (15.8 to 22.0$)$ & $1.47(0.23)$ \\
\hline Male genital & 435 & 1.81 (0.77 to 7.14 ) & 18.6 (14.9 to 22.5$)$ & 303 & 2.17 (0.70 to 9.20$)$ & 19.9 (15.4 to 24.8$)$ & $1.15(0.41)$ \\
\hline Others & 197 & $1.47(0.77$ to 7.30$)$ & 20.8 (15.3 to 26.7$)$ & 145 & 1.03 (0.40 to 3.70$)$ & $14.9(9.5$ to 21.3$)$ & $-\mathrm{b}$ \\
\hline \multicolumn{8}{|l|}{ Acute comorbidities } \\
\hline Acute renal failure & 630 & 0.90 (0.50 to 1.80$)$ & 7.4 (5.4 to 9.8 ) & 359 & 0.90 (0.37 to 1.93$)$ & 8.4 (5.6 to 11.9$)$ & $0.44(0.20)$ \\
\hline Septicemia & 2,013 & 1.02 (0.56 to 2.40$)$ & 9.8 (8.5 to 11.2$)$ & 1,155 & 0.93 (0.37 to 2.60$)$ & 10.2 (8.5 to 12.2$)$ & $0.94(0.24)$ \\
\hline Shock & 1,038 & 0.89 (0.44 to 2.07) & 9.0 (7.3 to 10.8$)$ & 547 & 0.87 (0.33 to 2.40$)$ & 9.4 (7.0 to 12.1$)$ & $0.96(0.20)$ \\
\hline Gl hemorrhage & 941 & 1.40 (0.60 to 4.70$)$ & $15.0(12.8$ to 17.4$)$ & 559 & $1.20(0.40$ to 4.27$)$ & $14.2(11.4$ to 17.3$)$ & $1.12(0.26)$ \\
\hline $\begin{array}{l}\text { Other injury and } \\
\text { poisoning }\end{array}$ & 729 & $2.90(1.00$ to 16.57$)$ & 28.4 (25.1 to 31.8$)$ & 392 & 2.07 (0.77 to 8.50$)$ & $21.8(17.7$ to 26.1$)$ & $1.61(0.45)$ \\
\hline Cerebrovascular disease & 592 & 2.37 (0.89 to 12.14$)$ & 25.2 (21.7 to 28.9$)$ & 426 & 2.67 (0.83 to 12.23$)$ & 25.0 (20.8 to 29.4$)$ & $1.61(0.38)$ \\
\hline \multicolumn{8}{|l|}{$\begin{array}{l}\text { Concurrent organ disorder } \\
\text { (chronic comorbidities) }\end{array}$} \\
\hline Hypertension & 615 & 2.60 (0.89 to 16.04$)$ & 27.3 (23.7 to 31.0$)$ & 354 & 2.20 (0.80 to 8.90$)$ & $21.7(17.3$ to 26.4$)$ & $1.83(0.44)$ \\
\hline COPD & 615 & 2.10 (0.87 to 9.97$)$ & 23.0 (19.6 to 26.4$)$ & 428 & $2.00(0.67$ to 8.73$)$ & 20.6 (16.8 to 24.6$)$ & $1.34(0.38)$ \\
\hline
\end{tabular}


Table 1 Characteristics and survival of cancer patients categorized by duration of mechanical ventilation (1998 to 2007). (Continued)

\begin{tabular}{llllllll}
\hline Hospital level & 977 & $1.40(0.63$ to 4.04$)$ & $12.6(10.5$ to 14.8$)$ & 694 & $1.40(0.57$ to 5.03$)$ & $14.3(11.7$ to 17.1$)$ & $1.17(0.31)$ \\
District & 3,058 & $1.44(0.64$ to 4.57$)$ & $14.4(13.2$ to 15.8$)$ & 1,772 & $1.27(0.50$ to 3.87$)$ & $12.2(10.7$ to 13.8$)$ & $1.04(0.22)$ \\
Regional & 4,976 & $1.67(0.70$ to 8.02$)$ & $20.5(19.3$ to 21.6$)$ & 2,672 & $1.40(0.53$ to 5.07$)$ & $15.6(14.2$ to 17.1$)$ & $1.37(0.18)$
\end{tabular}

${ }^{\mathrm{a}} \mathrm{Cl}$, confidence interval; COPD, chronic obstructive pulmonary disease; GI, gastrointestinal; IQR, interquartile range; $\mathrm{MV}$, mechanical ventilation; $\mathrm{SE}$, standard error of the mean. ${ }^{b}$ Life expectancy could not be calculated because of violation of the assumption of constant excess hazard or small numbers.

Incidence of prolonged mechanical ventilation

The overall incidence of cancer patients requiring PMV was 10.4 per 100 ICU admissions. The incidences of PMV in different types of cancer are summarized in Table 2. Lung cancer patients yielded the highest incidence of PMV (14.9 per 100 ICU admissions). Patients with liver cancer exhibited the lowest incidence of PMV (4.3 per 100 ICU admissions).

Survival rate, life expectancy and quality-adjusted life expectancy

The results of survival rate, life expectancy and QALE of the study populations categorized using different variables are summarized in Tables 1 and 2. Patients with metastatic cancer status have a generally poor prognosis, with a 1-yr survival rate of $5.9 \%$ (95\% confidence interval [CI], $4.6 \%$ to $7.3 \%$ ) and estimated life expectancy of 0.64 year. In addition, the life expectancies and QALEs are generally better in patients with head and neck or colorectal cancer. Those patients with liver or lung cancer had a poor prognosis.

\section{Prognostic factors}

The results of three multivariate Cox regression models are summarized in Table 3. Male gender, metastatic cancer and comorbidities of acute renal failure, shock, septicemia and gastrointestinal hemorrhage significantly predicted shorter survival after controlling for other risk factors. Patients treated in medical centers seem to have a slightly better prognosis after adjustment for other predictors (Table 3 ). In addition, age and period of receiving PMV treatment had no significant prognostic impact on survival for cancer patients.

\section{Discussion}

Although there are studies reporting the poor prognosis of patients with advanced cancer hospitalized in the ICU

Table 2 Incidence and the estimated quality-adjusted life expectancy for cancer patients undergone prolonged mechanical ventilation ${ }^{a}$

\begin{tabular}{|c|c|c|c|c|}
\hline \multirow[t]{2}{*}{ Type of cancer } & \multirow[t]{2}{*}{ Number of ICU admissions } & \multirow{2}{*}{$\begin{array}{l}\text { Incidence of PMV per } 100 \text { ICU } \\
\text { admissions }(95 \% \mathrm{CI})\end{array}$} & \multicolumn{2}{|c|}{ QALE in QALY units (SE) } \\
\hline & & & $\begin{array}{l}\text { Partial } \\
\text { cognition }\end{array}$ & $\begin{array}{l}\text { Poor } \\
\text { cognition }\end{array}$ \\
\hline Lung & 6,114 & 14.9 (8.4 to 23.5$)$ & $0.23(0.06)$ & $0.11(0.03)$ \\
\hline Others & 608 & 14.3 (8.4 to 23.5$)$ & $-\mathrm{b}$ & $-\mathrm{b}$ \\
\hline Male genital & 2,197 & $14.2(8.4$ to 23.5$)$ & $0.33(0.14)$ & $0.15(0.06)$ \\
\hline Brain \& nervous system & 1,490 & 14.0 (7.7 to 24.5$)$ & $0.35(0.19)$ & $0.16(0.08)$ \\
\hline $\begin{array}{l}\text { Lymphatic and } \\
\text { hematopoietic tissue }\end{array}$ & 2,242 & 13.3 (7.7 to 22.2$)$ & $0.35(0.16)$ & $0.16(0.06)$ \\
\hline Esophagus & 1,781 & 13.0 (6.9 to 22.2$)$ & $0.30(0.13)$ & $0.14(0.07)$ \\
\hline Skin & 579 & 13.1 (7.7 to 22.2$)$ & $-{ }_{-}^{b}$ & $-\mathrm{b}$ \\
\hline Thyroid & 432 & $12.3(6.9$ to 21.0$)$ & $-b$ & $-b$ \\
\hline Stomach & 2,647 & $11.1(6.2$ to 19.7$)$ & $0.28(0.13)$ & $0.13(0.04)$ \\
\hline Colorectal & 6,213 & $10.6(5.5$ to 18.4$)$ & $0.45(0.11)$ & $0.20(0.06)$ \\
\hline Urinary organs & 2,883 & $10.4(5.5$ to 18.4$)$ & $0.26(0.08)$ & $0.12(0.04)$ \\
\hline Bone and connective tissue & 339 & $10.3(5.5$ to 18.4$)$ & $-\mathrm{b}$ & $-\mathrm{b}$ \\
\hline Breast & 2,072 & $9.9(4.8$ to 17.1$)$ & $0.34(0.17)$ & $0.16(0.06)$ \\
\hline Head and neck & 7,074 & 8.8 (4.1 to 15.8 ) & $0.48(0.21)$ & $0.22(0.08)$ \\
\hline Female genital & 2,342 & 8.5 (4.1 to 15.8$)$ & $0.28(0.23)$ & $0.12(0.11)$ \\
\hline $\begin{array}{l}\text { Pancreas and other } \mathrm{Gl} \\
\text { organs }\end{array}$ & 1,097 & 8.0 (3.5 to 15.8$)$ & $-\mathrm{b}$ & $-b^{-1}$ \\
\hline Liver & 6,625 & 4.3 (1.6 to 10.2$)$ & $0.12(0.07)$ & $0.06(0.02)$ \\
\hline
\end{tabular}

${ }^{a} \mathrm{Cl}$, confidence interval; Gl, gastrointestinal; ICU, intensive care unit; QALY, quality-adjusted life year; SE, standard error of the mean. ${ }^{\mathrm{b}} \mathrm{QALE}$ could not be calculated because of violation of assumption or small numbers. 
Table 3 Independent risk factors for mortality in cancer patients undergone prolonged mechanical ventilation ${ }^{a}$

\begin{tabular}{|c|c|c|}
\hline \multirow[t]{2}{*}{ Variables } & \multicolumn{2}{|l|}{ Risk of death } \\
\hline & Crude HR $(95 \% \mathrm{Cl})$ & Adjusted $\mathrm{HR}^{\mathrm{b}}(95 \% \mathrm{Cl})$ \\
\hline \multicolumn{3}{|l|}{ Gender } \\
\hline Female & 1.00 & 1.00 \\
\hline Male & 1.07 (1.01 to 1.14$)$ & $1.12(1.04$ to 1.20$)$ \\
\hline \multicolumn{3}{|l|}{ Age (yr) } \\
\hline 17 to 64 & 1.00 & 1.00 \\
\hline 65 to 74 & 0.99 (0.92 to 1.07$)$ & 0.99 (0.91 to 1.07$)$ \\
\hline 75 to 84 & 0.96 (0.89 to 1.03$)$ & 1.02 (0.94 to 1.10$)$ \\
\hline 85 or older & $0.90(0.81$ to 1.01$)$ & 0.98 (0.87 to 1.10$)$ \\
\hline \multicolumn{3}{|l|}{ Extent of cancer } \\
\hline Local & 1.00 & 1.00 \\
\hline Metastatic & $1.56(1.45$ to 1.66$)$ & $1.53(1.42$ to 1.65$)$ \\
\hline \multicolumn{3}{|l|}{ Cancer type } \\
\hline Head and neck & 1.00 & 1.00 \\
\hline Bone and connective tissue & 2.08 (1.49 to 2.90$)$ & 2.06 (1.48 to 2.88$)$ \\
\hline Liver & 1.65 (1.43 to 1.90$)$ & 1.55 (1.34 to 1.78$)$ \\
\hline Lung & 1.58 (1.42 to 1.75$)$ & $1.45(1.30$ to 1.61$)$ \\
\hline Esophagus & $1.44(1.23$ to 1.69$)$ & $1.32(1.13$ to 1.54$)$ \\
\hline Lymphatic and hematopoietic tissue & $1.26(1.09$ to 1.45$)$ & $1.32(1.14$ to 1.52$)$ \\
\hline Urinary organs & $1.23(1.07$ to 1.43$)$ & 1.24 (1.07 to 1.43$)$ \\
\hline Female genital & 1.19 (1.01 to 1.40$)$ & 1.23 (1.03 to 1.46$)$ \\
\hline Pancreas and other Gl organs & 1.19 (0.96 to 1.48$)$ & 1.17 (0.94 to 1.47$)$ \\
\hline Thyroid & 1.14 (0.86 to 1.52$)$ & 1.17 (0.88 to 1.56$)$ \\
\hline Breast & 1.10 (0.94 to 1.29) & 1.14 (0.96 to 1.35$)$ \\
\hline Skin & 1.07 (0.84 to 1.36$)$ & 1.08 (0.84 to 1.38$)$ \\
\hline Stomach & 1.09 (0.9 to 1.26$)$ & 1.08 (0.93 to 1.25$)$ \\
\hline Brain and nervous system & 1.01 (0.8 to 1.19) & 1.04 (0.89 to 1.22$)$ \\
\hline Colorectal & 1.05 (0.93 to 1.17$)$ & 1.04 (0.92 to 1.17$)$ \\
\hline Male genital & 0.95 (0.82 to 1.10$)$ & 0.93 (0.80 to 1.09) \\
\hline Others & 1.28 (1.06 to 1.54$)$ & 1.14 (0.95 to 1.39$)$ \\
\hline \multicolumn{3}{|l|}{ Acute comorbidities $^{c}$} \\
\hline Acute renal failure & $1.43(1.28$ to 1.60$)$ & $1.46(1.30$ to 1.64$)$ \\
\hline Septicemia & 1.33 (1.24 to 1.43$)$ & $1.24(1.15$ to 1.34$)$ \\
\hline Shock & $1.32(1.21$ to 1.45$)$ & $1.22(1.10$ to 1.34$)$ \\
\hline Gl hemorrhage & 1.07 (0.98 to 1.18 ) & $1.10(1.01$ to 1.21$)$ \\
\hline Other injury and poisoning & 0.78 (0.70 to 0.87 ) & 0.83 (0.74 to 0.92) \\
\hline Cerebrovascular disease & 0.69 (0.62 to 0.77$)$ & 0.78 (0.69 to 0.87$)$ \\
\hline \multicolumn{3}{|l|}{$\begin{array}{l}\text { Concurrent organ disorder } \\
\text { (chronic comorbidities) }{ }^{c}\end{array}$} \\
\hline Hypertension & 0.74 (0.65 to 0.83$)$ & 0.82 (0.73 to 0.93$)$ \\
\hline COPD & 0.81 (0.73 to 0.91$)$ & 0.88 (0.79 to 0.98$)$ \\
\hline \multicolumn{3}{|l|}{ Hospital level } \\
\hline District & 1.00 & 1.00 \\
\hline Regional & 1.12 (1.02 to 1.23$)$ & 1.02 (0.93 to 1.12$)$ \\
\hline Medical center & 1.00 (0.91 to 1.09$)$ & 0.91 (0.83 to 1.00$)$ \\
\hline
\end{tabular}

${ }^{a} \mathrm{Cl}$, confidence interval; COPD, chronic obstructive pulmonary disease; $\mathrm{Gl}$, gastrointestinal. ${ }^{\mathrm{b}}$ Hazard ratio adjusted for cancer type, gender, age, extent of cancer, acute and chronic comorbidities, and hospital level. ${ }^{~}$ The reference group is without the comorbidity listed below.

and under mechanical ventilation, to the best of our knowledge, our study is the first to provide the crucial estimates of survival rates, life expectancies and QALE in these patients categorized by metastatic status and types of cancer based on a national database, as summarized in Tables 1 and 2. We found the median survival of cancer patients under more than 7 days of mechanical ventilation is generally less than 2 months, with the exception 
of those with cancer of the head, neck, esophagus, skin or nervous system. Half of those patients under PMV survived less than 1.4 months with an overall 1-yr survival rate of $14.3 \%$ ( $95 \% \mathrm{CI}, 13.3 \%$ to $15.3 \%$ ), which is generally poorer than that of patients with other comorbidities [13].

Among different types of cancer, those occurring in the lung and nervous system seemed to have the highest incidence of ICU admissions (Table 2). This might be associated with direct tumor involvement of the respiratory tract and/or the control of ventilation. Patients with liver cancer were found to exhibit the lowest incidence of PMV, which may be related to their lower survival rate and life expectancy (Table 1).

Previous studies of cancer patients requiring ventilator support in the ICU could differentiate cancer types into only solid and hematological malignancy because of small numbers [7,26,27]. Among them, Soares et al. reported a $60 \%$ rate of 6-month mortality for 163 patients who had a prolonged ICU length of stay (21 days or longer), and the number of organ failures, old age and poor performance status were significantly associated with poor outcomes [27]. Nonetheless, in our study, with 10-yr follow-up of a nationwide collection of cases, we have been able to detect cancer occurring in different organ systems as a predictor of lifetime mortality after adjustment for multiple confounders (Table 3). It is also noteworthy that age is not related to the outcomes in our study, which might indicate that cancer patients under PMV are usually at the most severe stage, with a life expectancy of $1.21 \mathrm{yr}$. Thus, age did not appear to influence such an overall poor prognosis.

Critical care with mechanical ventilation has been advocated as a therapeutic trial for critically ill cancer patients, but failure of such care might signal a need for a transition from curative to palliative care $[28,29]$. Patients and their families may be more likely to accept revision of the goal of care when there is little hope for meaningful recovery [30]. In many occasions, however, stakeholders have too little important prognostic information, especially with regard to reliable estimates of life expectancies for different conditions, to use in making decisions [31]. The long-term outcomes and prognostic factors for PMV cancer patients in our study may thus be useful for communication among all stakeholders to facilitate patient-centered clinical decisions and possible early integration of palliative care, which is very crucial in Taiwan, where regulations for extubation are rather restrictive. This used to require the signatures of all firstdegree relatives; but, in 2013, the rule was changed to require only one signature.

In addition to survival, a more ideal outcome evaluation must also take QoL into consideration. Assuming that the QoL of these patients is similar to that of other PMV patients, we tried to categorize them into patients with poor cognition and those with partial cognitive ability.
Using that method, the overall QALE would be about 0.17 to 0.37 QALY. Even for patients with colorectal cancer requiring PMV who had the longest survival, the QALE was only 0.20 to 0.45 QALYs for patients with poor cognition and those with partial cognitive ability, respectively. Further evaluation of the cost per QALY in another study for patients under PMV found that cancer patients spent $\$ 64,708$ and US\$148,829 per QALY with partial versus poor cognition, respectively. Both figures cost more than three times Taiwan's gross domestic product and were not considered cost-effective based on criteria suggested by the World Health Organization's CHOosing Interventions that are Cost-Effective (WHO-CHOICE) guideline [32]. The out-of-pocket expenses were estimated to be about one-third those including such spending [14]. Thus, we recommend that palliative care be considered early, especially among patients with metastasis, to avoid a prolonged dying process.

Our study has the following limitations. First, the database did not contain any information regarding the parameters of prior performance status, which has been reported to be predictive for long-term survival in critically ill cancer patients, including those requiring mechanical ventilation $[9,33,34]$. As poor performance status was usually associated with advanced or metastatic cancer [35], the HR we obtained in this study might be overestimated. Second, because the billing records in the NHIRD provide neither the exact date of tracheostomy nor the main reasons for ICU admission, we were unable to stratify these patients by the stability of their clinical course. Further prospective study is warranted to clarify this issue. Third, decisions to limit therapy, and particularly "do not resuscitate" (DNR) orders, were not recorded in the NHI data. Patients with DNR orders may prevent the use of aggressive treatment, which may be a crucial confounding factor in the survival analysis. Although we recommend that future studies take this factor into account, the magnitude of potential bias resulting from this factor might be quite limited in our present study because all cancer patients under PMV were already intubated, and, because of the legal restrictions in Taiwan before 2011, no one, even with the consent of all family members, was allowed to withdraw PMV. Thus, considerations for these patients were presumed to be those without DNR consent. However, the adaptation of PMV incidence in our study should be cautious because life-supporting treatment would be allowed to be withdrawn in other countries under certain circumstances [36,37].

\section{Conclusions}

Cancer patients undergoing mechanical ventilation for more than 7 days usually had a poor long-term outcome, especially those under PMV, which we defined as continuous 
mechanical ventilation for more than 21 days. In our opinion, palliative care should be considered early in cancer patients with metastases. The extent of treatment and end-of-life issues should be openly discussed in the early stages of care for cancer patients. In Taiwan, too often this discussion begins after a patient's loss of decision-making ability, suggesting general ignorance of the principle of respect for autonomy. Our results also call to attention the cost-effectiveness of current policies in the care of cancer patients undergoing PMV.

\section{Key messages}

- Half of cancer patients under PMV survived less than 1.4 months, and the overall 1-yr survival rate was $14.3 \%$.

- Cancer of the liver and lung and metastasis independently predict shorter survival.

- We recommend that palliative care be considered early in mechanically ventilated patients with metastatic cancer.

\section{Abbreviations \\ CCS: Clinical Classifications Software; NHI: National Health Insurance; PMV: prolonged mechanical ventilation; QALE: quality-adjusted life expectancy.}

\section{Competing interests}

The authors declare that they have no competing interests.

\section{Authors' contributions}

CYS performed the analysis and interpretation of data and drafted and revised the manuscript. $\mathrm{MCH}$ was involved in the acquisition of data, data analysis, interpretation of data and revision of the manuscript. HML was involved in the acquisition of data and data analysis. LC contributed to the study design, acquisition of data, interpretation of data and revision of the manuscript. SJH contributed to the interpretation of data and revision of the manuscript. JDW contributed to the study concept and design, interpretation of data, and drafting and revision of the manuscript. All authors approved the final version of the manuscript submitted for publication.

\section{Acknowledgements \\ The present work was partially supported by grants from the National Science Council (grants 98-2341-B-002-129 and 99-2628-B-006-036-MY3) and National Health Research Institutes (grants PH-099-PP-19 and PH-100-PP-19). We thank Chian-Wei Chen for assistance with the statistical analysis used in preparing the manuscript.}

\section{Authors' details}

'Department of Family Medicine, National Taiwan University Hospital JinShan Branch, No.51, Nanshih, Jinshan District, New Taipei City 208, Taiwan. ${ }^{2}$ Department of Public Health, National Cheng Kung University College of Medicine, No.1, University Road, Tainan 701, Taiwan. ${ }^{3}$ Institute of Population Health Sciences, National Health Research Institutes, 35 Keyan Road, Zhunan 350, Taiwan. ${ }^{4}$ Institute of Public Health, School of Medicine, National YangMing University, No.155, Sec.2, Linong Street, Taipei 112, Taiwan. ${ }^{5}$ National Taiwan University Hospital Jin-Shan Branch, No.51, Nanshih, Jinshan District, New Taipei City 208, Taiwan. 'Department of surgery, College of Medicine, National Taiwan University, No.1, Sec.1, Jen-Ai Road, Taipei 100, Taiwan. ${ }^{7}$ Departments of Internal Medicine and Occupational and Environmental Medicine, National Cheng Kung University Hospital, No.138, Sheng-Li Road, Tainan 704, Taiwan.

Received: 20 September 2012 Revised: 30 September 2012 Accepted: 22 July 2013 Published: 22 July 2013

\section{References}

1. Coleman MP, Quaresma M, Berrino F, Lutz JM, De Angelis R, Capocaccia R, Baili P, Rachet B, Gatta G, Hakulinen T, Micheli A, Sant M, Weir HK, Elwood JM, Tsukuma H, Koifman S, Azevedo e Silva G, Francisci S, Santaquilani M, Verdecchia A, Storm HH, Young JL, Concord Working Group: Cancer survival in five continents: a worldwide population-based study (CONCORD). Lancet Oncol 2008, 9:730-756.

2. Kinsey $T$, Jemal A, Liff J, Ward E, Thun M: Secular trends in mortality from common cancers in the United States by educational attainment, 19932001. J Natl Cancer Inst 2008, 100:1003-1012.

3. Azoulay E, Thiéry G, Chevret S, Moreau D, Darmon M, Bergeron A, Yang K, Meignin V, Ciroldi M, Le Gall JR, Tazi A, Schlemmer B: The prognosis of acute respiratory failure in critically ill cancer patients. Medicine (Baltimore) 2004, 83:360-370.

4. Chaoui D, Legrand O, Roche N, Cornet M, Lefebvre A, Peffault de Latour R, Sanhes L, Huchon G, Marie JP, Rabbat A: Incidence and prognostic value of respiratory events in acute leukemia. Leukemia 2004, 18:670-675.

5. Kress JP, Christenson J, Pohlman AS, Linkin DR, Hall JB: Outcomes of critically ill cancer patients in a university hospital setting. Am J Respir Crit Care Med 1999, 160:1957-1961.

6. Staudinger T, Stoiser B, Müllner M, Locker GJ, Laczika K, Knapp S, Burgmann H, Wilfing A, Kofler J, Thalhammer F, Frass M: Outcome and prognostic factors in critically ill cancer patients admitted to the intensive care unit. Crit Care Med 2000, 28:1322-1328.

7. Soares M, Carvalho MS, Salluh Jl, Ferreira CG, Luiz RR, Rocco JR, Spector N: Effect of age on survival of critically ill patients with cancer. Crit Care Med 2006, 34:715-721.

8. Taccone FS, Artigas AA, Sprung CL, Moreno R, Sakr Y, Vincent JL: Characteristics and outcomes of cancer patients in European ICUs. Crit Care 2009, 13:R15.

9. Soares M, Caruso P, Silva E, Teles JM, Lobo SM, Friedman G, Dal Pizzol F, Mello PV, Bozza FA, Silva UV, Torelly AP, Knibel MF, Rezende E, Netto JJ, Piras C, Castro A, Ferreira BS, Réa-Neto A, Olmedo PB, Salluh Jl, Brazilian Research in Intensive Care Network (BRICNet): Characteristics and outcomes of patients with cancer requiring admission to intensive care units: a prospective multicenter study. Crit Care Med 2010, 38:9-15.

10. Carson SS: Outcomes of prolonged mechanical ventilation. Curr Opin Crit Care 2006, 12:405-411.

11. Bureau of National Health Insurance website [in Chinese]. [http://www. nhi.gov.tw/nhi/index.aspx].

12. Cheng SH, Jan IS, Liu PC: The soaring mechanic ventilator utilization under a universal health insurance in Taiwan. Health Policy 2008, 86:288-294.

13. Hung MC, Lu HM, Chen L, Hu FC, Chan SY, Yan YH, Fan PS, Lin MS, Chen CR, Kuo LC, Yu CJ, Wang JD: Life expectancies and incidence rates of patients under prolonged mechanical ventilation: a population-based study during 1998 to 2007 in Taiwan. Crit Care 2011, 15:R107.

14. Hung MC, Lu HM, Chen L, Lin MS, Chen CR, Yu CJ, Wang JD: Cost per QALY (quality-adjusted life year) and lifetime cost of prolonged mechanical ventilation in Taiwan. PLoS One 2012, 7:e44043.

15. Macintyre NR, Epstein SK, Carson S, Scheinhorn D, Christopher K, Muldoon S, National Association for Medical Direction of Respiratory Care: Management of patients requiring prolonged mechanical ventilation: report of a NAMDRC consensus conference. Chest 2005, 128:3937-3954.

16. National Health Insurance Managed Care Demonstration Program for Ventilator Dependent Patients [in Chinese]. [http://www.nhi.gov.tw/ webdata/webdata.aspx? menu=8\&menu_id=498\&WD_ID=498\&webdata_id=942].

17. Healthcare Cost and Utilization Project (HCUP), Agency for Healthcare Research and Quality (AHRQ): Clinical Classifications Software (CCS) for ICD-9-CM.[http://www.hcup-us.ahrq.gov/toolssoftware/ccs/ccs.jsp].

18. Lin MS, Yan YH, Wang JD, Lu HM, Chen L, Hung MC, Fan PS, Chen CR: Improved survival for an integrated system of reduced intensive respiratory care for patients requiring prolonged mechanical ventilation. Respir Care 2013, 58:517-524.

19. Hwang JS, Wang JD: Monte Carlo estimation of extrapolation of qualityadjusted survival for follow-up studies. Stat Med 1999, 18:1627-1640.

20. Fang CT, Chang YY, Hsu HM, Twu SJ, Chen KT, Lin CC, Huang LY, Chen MY, Hwang JS, Wang JD, Chuang CY: Life expectancy of patients with newlydiagnosed HIV infection in the era of highly active antiretroviral therapy. QJM 2007, 100:97-105. 
21. Hwang JS, Wang JD: Integrating health profile with survival for quality of life assessment. Qual Life Res 2004, 13:1-14.

22. iSQoL: integration of Survival with Quality of Life [software]. [http://www. stat.sinica.edu.tw/isqo//].

23. Hwang JS, Tsauo JY, Wang JD: Estimation of expected quality adjusted survival by cross-sectional survey. Stat Med 1996, 15:93-102.

24. Hung MC, Yan YH, Fan PS, Lin MS, Chen CR, Kuo LC, Yu CJ, Wang JD: Estimation of quality-adjusted life expectancy in patients under prolonged mechanical ventilation. Value Health 2011, 14:347-353.

25. Hung MC, Yan YH, Fan PS, Lin MS, Chen CR, Kuo LC, Yu CJ, Yao G, Hsieh CL, Wang JD: Measurement of quality of life using EQ-5D in patients on prolonged mechanical ventilation: comparison of patients, family caregivers, and nurses. Qual Life Res 2010, 19:721-727.

26. Groeger JS, White P Jr, Nierman DM, Glassman J, Shi W, Horak D, Price K: Outcome for cancer patients requiring mechanical ventilation. J Clin Oncol 1999, 17:991-997.

27. Soares M, Salluh JI, Torres VB, Leal JV, Spector N: Short- and long-term outcomes of critically ill patients with cancer and prolonged ICU length of stay. Chest 2008, 134:520-526.

28. Truog RD, Campbell ML, Curtis JR, Haas CE, Luce JM, Rubenfeld GD, Rushton CH, Kaufman DC, American Academy of Critical Care Medicine: Recommendations for end-of-life care in the intensive care unit: a consensus statement by the American College of Critical Care Medicine. Crit Care Med 2008, 36:953-963.

29. Azoulay E, Soares M, Darmon M, Benoit D, Pastores S, Afessa B: Intensive care of the cancer patient: recent achievements and remaining challenges. Ann Intensive Care 2011, 1:5.

30. Heyland DK, Dodek P, Rocker G, Groll D, Gafni A, Pichora D, Shortt S, Tranmer J, Lazar N, Kutsogiannis J, Lam M, Canadian Researchers End-of-Life Network (CARENET): What matters most in end-of-life care: perceptions of seriously ill patients and their family members. CMAJ 2006, 174:627-633.

31. Nelson JE, Mercado AF, Camhi SL, Tandon N, Wallenstein S, August Gl, Morrison RS: Communication about chronic critical illness. Arch Intern Med 2007, 167:2509-2515

32. World Health Organization, CHOosing Interventions that are Cost Effective (WHO-CHOICE): Cost-effective Threshold. [http://www.who.int/choice/ costs/CER thresholds/en/].

33. Soares M, Salluh Jl, Spector N, Rocco JR: Characteristics and outcomes of cancer patients requiring mechanical ventilatory support for $>24 \mathrm{hrs}$. Crit Care Med 2005, 33:520-526.

34. Toffart AC, Minet C, Raynard B, Schwebel C, Hamidfar-Roy R, Diab S, Quetant S, Moro-Sibilot D, Azoulay E, Timsit JF: Use of intensive care in patients with nonresectable lung cancer. Chest 2011, 139:101-108.

35. Salpeter SR, Malter DS, Luo EJ, Lin AY, Stuart B: Systematic review of cancer presentations with a median survival of six months or less. J Palliat Med 2012, 15:175-185.

36. Sprung CL, Cohen SL, Sjokvist P, Baras M, Bulow HH, Hovilehto S, Ledoux D, Lippert A, Maia P, Phelan D, Schobersberger W, Wennberg E, Woodcock T, for the Ethicus Study Group: End-of-life practices in European intensive care units: the Ethicus Study. JAMA 2003, 290:790-797.

37. Fumis RR, Deheinzelin D: Respiratory support withdrawal in intensive care units: families, physicians and nurses views on two hypothetical clinical scenarios. Crit Care 2010, 14:R235.

\section{Submit your next manuscript to BioMed Central and take full advantage of:}

- Convenient online submission

- Thorough peer review

- No space constraints or color figure charges

- Immediate publication on acceptance

- Inclusion in PubMed, CAS, Scopus and Google Scholar

- Research which is freely available for redistribution

Submit your manuscript at www.biomedcentral.com/submit
Ciomed Central 